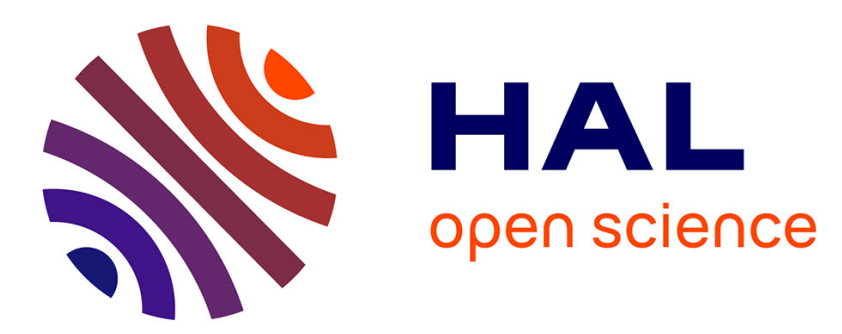

\title{
Evidence of Unfolded Protein Translocation through a Protein Nanopore
}

\author{
Manuela Pastoriza-Gallego, Marie-France Breton, Françoise Discala, Loïc
}

Auvray, Jean-Michel Betton, Juan Pelta

\section{To cite this version:}

Manuela Pastoriza-Gallego, Marie-France Breton, Françoise Discala, Loïc Auvray, Jean-Michel Betton, et al.. Evidence of Unfolded Protein Translocation through a Protein Nanopore. ACS Nano, 2014, 8 (11), pp.11350-11360. 10.1021/NN5042398 . hal-02112337

\section{HAL Id: hal-02112337 \\ https://hal.science/hal-02112337}

Submitted on 3 Jun 2021

HAL is a multi-disciplinary open access archive for the deposit and dissemination of scientific research documents, whether they are published or not. The documents may come from teaching and research institutions in France or abroad, or from public or private research centers.
L'archive ouverte pluridisciplinaire HAL, est destinée au dépôt et à la diffusion de documents scientifiques de niveau recherche, publiés ou non, émanant des établissements d'enseignement et de recherche français ou étrangers, des laboratoires publics ou privés. 


\title{
Evidence of Unfolded Protein Translocation through a Protein Nanopore
}

\author{
Manuela Pastoriza-Gallego, $†$ Marie-France Breton, † Franc-oise Discala, $†$ LoI“c Auvray,§ Jean-Michel Betton,^ \\ and Juan Pelta* $, \dagger, \ddagger$ \\ TCNRS-UMR 8587, LAMBE, Université de Cergy-Pontoise, 2 avenue A. Chauvin, 95302 Cergy-Pontoise Cedex \\ France, $¥$ CNRS-UMR 8587, LAMBE, Université d' $\square$ Evry, \\ Bd F. Mitterrand, $91025 \square$ Evry France, §CNRS UMR 7057, Laboratoire Matière et Systèmes Complexes, \\ Université Paris Diderot, F-75205 Paris, France, and \\ ^Unité de Microbiologie Structurale, CNRS UMR 3528, Institut Pasteur, 28, rue du Docteur Roux, 75724 Paris \\ cedex 15 France
}

\begin{abstract}
Protein nanopores are mainly used to study transport, unfolding, intrinsically disordered proteins, protein-pore interactions, and protein ligand complexes. This single-molecule sensor for biomedical and biotechnological applications is promising but until now direct proof of protein translocation through a narrow channel is lacking. Here, we report the translocation of a chimera molecule through the aerolysin nanopore in the presence of a denaturing agent, guanidium chloride $(1.5 \mathrm{M})$ and $\mathrm{KCl}(1 \mathrm{M})$. The chimera molecule is composed of the recombinant MalE protein with a unique cysteine residue at the C-terminal position covalently linked to a single-stranded DNA oligonucleotide. Real-time polymerase chain reaction (PCR) was used to detect the presence of chimera molecules that have been effectively translocated from the cis to trans chamber of the set up. Comparing the electrical signature of the chimera related to the protein or oligonucleotide alone demonstrates that each type of molecule displays different dynamics in term of transport time, event frequency, and current blockade. This original approach provides the possibility to study protein translocation through different biological, artificial, and biomimetic nanopores or nanotubes. New future applications are now conceivable such as protein refolding at the nanopore exit, peptides and protein sequencing, and peptide characterization for diagnostics.
\end{abstract}

KEYWORDS: nanopore $\cdot$ aerolysin $\cdot$ translocation $\cdot$ qRT-PCR $\cdot$ maltose binding protein $\cdot$ single molecule $\cdot$ protein folding

nanopore coupled with an electric
detection method is a powerful tool
to investigate fundamental biological, chemical, or physical problems at the single-molecule level and to develop potential future applications. ${ }^{1-13}$ These biotechnological and medical applications concern fast sequencing of nucleic acids ${ }^{9,11}$ or proteins, ${ }^{14}$ detection of biomarkers in biofluid associated with human disease, ${ }^{15,16}$ misfolded proteins, ${ }^{17-19}$ protein stability and folding, ${ }^{20-22}$ development of singlemolecule mass spectrometry for polymers. ${ }^{23,24}$ Proteins nanopores are mainly used to study protein translocation, ${ }^{25-27}$ protein unfolding by denaturing agent, ${ }^{21,28,29}$ electrical force, ${ }^{22} \mathrm{pH}^{30}$ or by molecular motor, ${ }^{14}$ to study protein traffic in cells, ${ }^{8}$ to probe disordered protein folding by divalent cations $^{31}$ or by a peptide ligand, ${ }^{17}$ to detect native proteins with aptamers covalently attached to the nanopore ${ }^{32,33}$ or with directed evolution approach to design and obtain new channels. ${ }^{34,35}$ Most experiments to explore protein dynamics use artificial nanopores: solid-state nanopores, ${ }^{36-44}$ functionalized conical gold nanotubes, ${ }^{45,46}$ glass nanopore, ${ }^{47}$ or hybrid nanopores coated with natural lipids ${ }^{48}$ or with a chemical modification to attach antibodies ${ }^{49}$ instead of protein channels, but their diameter is generally larger than that of proteins to be translocated and their specificity and sensitivity are lower than that of biological channels, except for hybrid nanopores. The main advantage of artificial nanopores is their intrinsic stability allowing the accumulation of translocated molecules during long experiments and then facilitating their detection. ${ }^{38}$ Using protein nanopores we could expect to develop more sensitive applications, but evidence of protein translocation through these pores is lacking. This is mainly due to the sensitivity limitation of classical protein detection methods that can detect about 1 pg of protein, and often they 
use antibodies making the experiments longer, costly, and complicated. The setup for protein transport through protein nanopores is limited by both the duration time and applied voltage, thus restricting the amount of translocated protein. Only one study has already demonstrated the translocation of the light chain protease through the heavy chain channel of botulinum neurotoxin, but protease activity after translocation was assessed after the insertion of more than 2000 channels. $^{50}$

Twenty years ago, DNA translocation through an alpha-hemolysin channel was demonstrated by polymerase chain reaction (PCR). ${ }^{51}$ Later, experiments were performed to study protein entry and transport through other protein channels with an indirect evidence of translocation as a decrease of dwell time as a function of electrical force ${ }^{26,52}$ and an increase of this time as a function of molecular weight. ${ }^{26,53,54}$

To be transported through protein channels, native proteins must be unfolded. Therefore, their immunodetection by antibodies after translocation required a reversible renaturation or refolding process. With native protein bovine serum albumin, direct proof of translocation with antibodies was obtained using a large solid-state nanopore. ${ }^{38}$ We report a novel approach to demonstrate that electrical events detected with denatured proteins going through a single protein nanopore are truly translocation events. Since direct detection of proteins is really compromised, we design a chimera molecule consisting in a recombinant protein covalently linked to an oligonucleotide to allow amplification by quantitative reverse transcription PCR (qRT-PCR) (Figure 1). In contrast with other previous results, ${ }^{50,55}$ we describe here the first assay to directly detect translocated molecules, and not their activity, using single protein channels.

\section{RESULTS AND DISCUSSION}

Chimera Design, Preparation, Characterization and qRT-PCR Experiments. A 60 base-oligonucleotide, designed for the detection of bluetongue in routine laboratories, was used as a DNA template for amplification by qRT$P C R .^{56}$ This synthetic oligonucleotide was modified to contain an amino group in the $5^{\prime}$ end. The recombinant maltose-binding protein (MalE) was modified by substituting its C-terminal lysine by a unique cysteine residue. These modifications in both molecules were introduced to chemically react with the heterobifunctional cross-linker SPDP (for details, see Methods section). After the conjugation reaction, the MalE-DNA chimera molecule was purified and characterized before using it in translocation experiments. A scheme of this chimera construction is shown in Figure 1a. Polyacrylamide gel electrophoresis analysis showed that the purified MalE-DNA molecule had the expected molecular size, and revealed the presence of few dimeric MalE K370C species because of cysteine oxidation (Figure $1 \mathrm{~b}$, left). However, when there was a separation by polyacrylamide gel electrophoresis in the presence of ethidium bromide, only the chimera molecule containing DNA was detected (Figure 1b, right).

To determine whether the presence of a protein attached to an oligonucleotide could influence our qRT-PCR assay, we first generated standard curves by serial dilutions of purified OCMN5 oligonucleotide or MalE-OCMN5 chimera (Figure 2). Fluorescence increase during amplification was measured (Figure 2a). We have represented the evolution of threshold cycle variation as a function of the number of molecules, oligonucleotide, and chimera, previously calculated by spectrophotometry methods (Figure $2 b$ ). After establishing a standard curve between 1000 and $10^{10}$ molecules (Figure 2b), we have adjusted all experimental data with a fit represented in green in the figure. At a very low molecule number, we can observe a little difference in chimera values related to the oligonucleotide ones. This difference could be due to less efficient priming near the $5^{\prime}$ end of DNA coupled to the protein during amplification. A previously more complex chimeric system of detection by PCR was published. ${ }^{57}$ The sensitivity is similar to our detection system but is not adapted to protein translocation experiments.

Dynamics of Chimera, Protein, Oligonucleotide Molecules. To further analyze translocation of chimera, we have also compared electrical signatures and dynamics of the three kinds of molecules, chimera, protein alone, and oligonucleotide alone through aerolysin (Figure 3). From the current traces, we observed short and long spikes (Figure $3 \mathrm{a}, \mathrm{c}, \mathrm{e}$ ). Detail of these current traces, $V=70 \mathrm{mV}$, focused on typical long blockade duration events for each type of molecule, chimera (Figure $3 b$ ), protein (Figure 3e), and oligonucleotide (Figure $3 \mathrm{~h}$ ), showed that their duration is different and specific. The short spikes time is similar for the three type of molecules, around $0.1 \mathrm{~ms}$ (Figure $3 \mathrm{c}$,f,i. We found for each species used that the mean blockade frequency, obtained from the blockade histograms (Supporting Information, Figure S2) is proportional to molecule concentration (Figure 3j). For the protein, the frequency is higher than for the oligonucleotide or chimera. Dwell time is independent of the molecule concentration under experimental conditions. Duration of events is deduced from the distribution of blockade duration (Supporting Information, Figure S2). The transport time of chimera $(1091 \pm 80 \mu \mathrm{s})$ corresponds to the dwell time contribution of protein alone $(658 \pm 30 \mu \mathrm{s})$ and oligonucleotide alone $(486 \pm 27 \mu \mathrm{s})$ (Figure $3 \mathrm{k}$ ). The existence of straddling times (short spikes) (Figure $3 \mathrm{c}, \mathrm{f,i}$ and transport times (long spikes) (Figure $3 \mathrm{~b}, \mathrm{e}, \mathrm{h}$ ) have been described previously for protein alone with aerolysin channel ${ }^{26}$ and for oligonucleotides with alpha-hemolysin channel. ${ }^{51}$ At the same protein concentration, $3 \mu \mathrm{M}$, we have found the same event 
a)

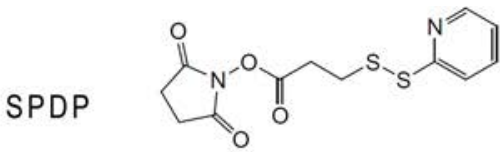

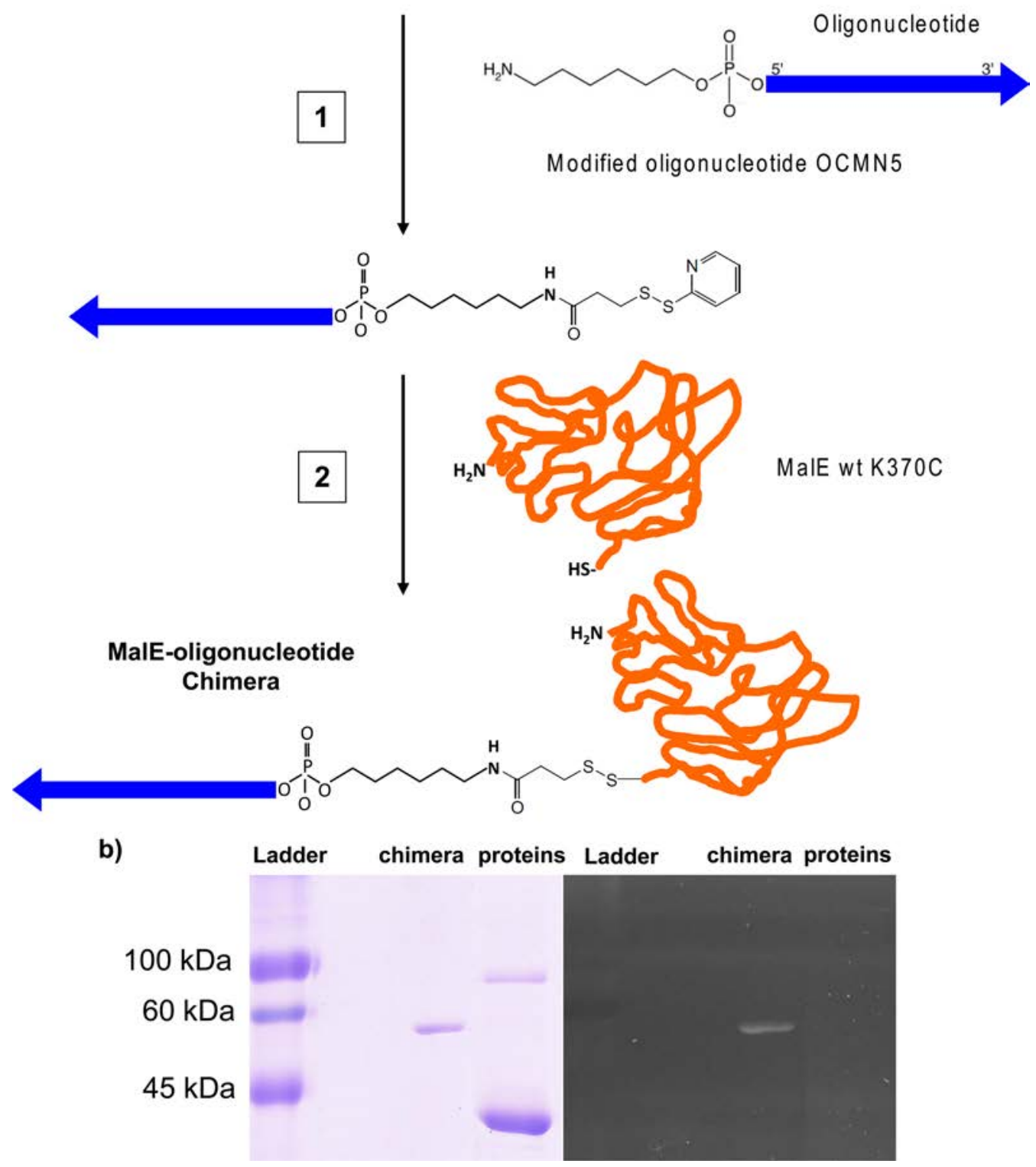

Figure 1. Chimera construction and purification. (a) Scheme of chimera construction A 60 nucleotide synthetic sequence with an amino group in $5^{\prime}$ DNA extremity was coupled to a recombinant MalE wt protein with a C-terminal amino acid substitution of lysine to cysteine. An amino group from the modified oligonucleotide was chemically coupled to the cysteine of the protein using SPDP (N-succinimidyl 3-(2-pyridyldithio) propionate) in two steps. First, amino from oligonucleotide was modified with the SPDP (1). After that, protein was coupled to the "activated" oligonucleotide (2) and molecules were separated by two chromatographic steps, desalting and gel filtration. (b) SDS-PAGE analysis after chimera purification. Left, Coomassie bleu coloration. Right, ethidium bromide signal under UV light. Lane 1, molecular weight marker, ladder; lane 2, chimera, lane 3, MalE K370C (a small amount of dimeric MalE is visible because of oxidation). Chimera concentration was calculated using spectrophotometric measures at 280 and $260 \mathrm{~nm}\left(E_{260} \mathrm{~nm}=588700 \mathrm{M}^{-1} \mathrm{~cm}^{-1}\right.$ and $\left.E_{280} \mathrm{~nm}=337520.1 \mathrm{M}^{-1} \mathrm{~m}^{-1}\right)$.

frequency inside standard deviations, ( $f($ MalEwt) $=$ $\left.15.2 \pm 1.8 \mathrm{~s}^{-1}, f\left(\mathrm{MaIE}_{\mathrm{K} 370 \mathrm{C}}\right)=14.3 \pm 1.7 \mathrm{~s}^{-1}\right)$ and dwell time $\left(t\left(\mathrm{MalE}_{\mathrm{wt}}\right)=725 \pm 80 \mu \mathrm{s}, t\left(\mathrm{MalE}_{\mathrm{K} 370 \mathrm{C}}\right)=596 \pm\right.$ $74 \mu \mathrm{s})$, respectively, for the wild-type protein and for the mutant protein with cysteine residue at the C-terminal position. To check if a current blockade could be associated with a type of molecule, we have fitted the distributions of events as a function of current blockade ratio (\%) for chimera, protein, and oligonucleotide with a Gaussian function (Figure $4 b, d, f$ ). We can observe a different normalized blockade ratio for the protein and the oligonucleotide for the deeper current drop (Table 1). The deep current blockade of the chimera molecule, $72 \pm 14 \%$, is between that for the protein or oligonucleotide alone.

A theoretical value of the current blockade ratio could be estimated making an approximation of the 

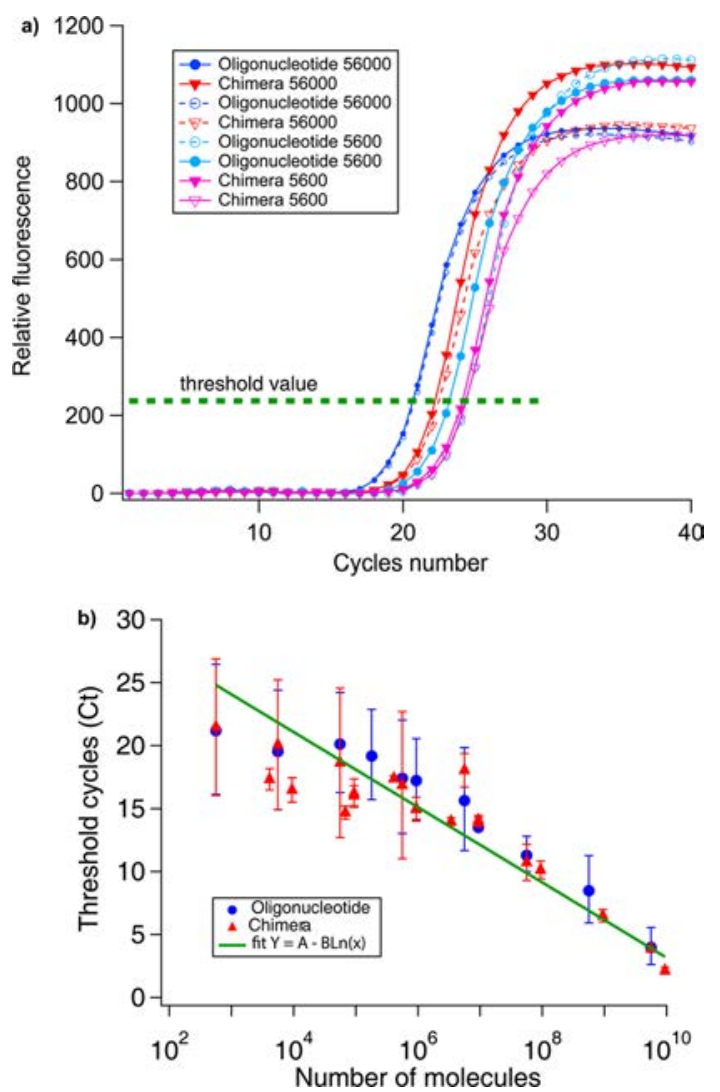

Figure 2. Chimera detection by qRT-PCR. (a) Cycle threshold $(\mathrm{Ct})$ calculation. Standard curves of amplification were done using known quantities of chimera (triangle) and oligonucleotide (circles). The range used in these amplifications goes from 1000 molecules to $10^{10}$ molecules. We can follow the number of amplified molecules per cycle using SYBRgreen fluorescence (incorporated during amplification reaction). These sigmoid curves allow us to set a threshold value in the exponential phase that will determine the $(\mathrm{Ct})$ for each amplified point. We give an example for 5600 and 56000 molecules (oligonucleotide or chimera) from two different experiments. (b) Standard curve for chimera quantification. Known amounts of chimera (red) or oligonucleotide (blue) were used to establish a standard curve of $(\mathrm{Ct})$ versus number of molecules. Green line corresponds to the fit of both molecules, $y=A-B \operatorname{Ln}(x)$, with $y=(\mathrm{Ct}), A=33 \pm$ $0.4, B=1.29 \pm 0.02$ and $x$ is the number of molecules. More than 10 different experiments were done for the standard curve calculations for chimera and oligonucleotide. In each experiment, measures were done at least in triplicate.

volume occupied by the chimera molecule inside the pore. The predicted volume occupied by the unfolded chain, with a thickness or persistence length of about $0.66 \mathrm{~nm}$, for the unfolded protein part of chimera, passing through the aerolysin channel represents at least $60 \%$ of current blockade. The short current drop events detected here, ( $\leq 30 \%$ of current blockade) could not be associated with translocation events. Long events with a current drop superior to $60 \%$ of blockade ratio could be associated with transport events (Table 1).

A recent study probed the translocation and unfolding dynamics of a folded small protein of 108 amino acids (thioredoxin) linked to DNA by electrical driving force. ${ }^{22}$ This paper shows the ability to unzip native protein attached to single-stranded DNA through a single alpha-hemolysin channel with applied voltage. They could detect four steps in the translocationunfolding process. The authors have also studied the effect of mutations on the constant rates between these steps. Finally, experiments in the presence or absence of a denaturing agent concluded that DNA was driving molecules through the alpha-hemolysin pore. In this interesting work, there is no direct evidence of protein translocation through the nanopore.

Unfortunately, we cannot develop a chimera unzipping assay without a denaturing agent in our experimental conditions using the aerolysin nanopore. The aerolysin channel is voltage sensitive, ${ }^{58}$ and remains open at $70 \mathrm{mV}$. Furthermore, in our experimental conditions with $1 \mathrm{M}$ guanidium chloride, pore stability is compromised at higher voltages. Other experiments from our laboratory show that the maltose binding protein is stable up to $200 \mathrm{mV}$ in the chimera form using the alpha-hemolysin channel (Payet et al; manuscript in preparation). In our experimental conditions, the protein side of the chimera is probably entering the aerolysin pore first, and this would enable two levels of current signal to be detected during translocation as it is shown in the paper of Rodriguez-Larrea and Bayley. We probably do not have enough resolution to detect a two-step signal expected when chimera is going through the pore, but the direct proof of this transport through the nanopore is shown with PCR assays. In the study of Rodriguez-Larrea and Bayley, the ionic current level of the empty pore is around $300 \mathrm{pA}$, the authors work with $2 \mathrm{M} \mathrm{KCl}$ and an alpha-hemolysin pore. Here, the ionic current of the aerolysin channel is around $65 \mathrm{pA}$. We cannot increase the salt concentration to improve the resolution because at high salt concentration unfolded proteins will precipitate by salting out.

We wonder why the unfolded protein enters first in the nanopore. The charge density on the singlestranded DNA (one negative charge each nucleotide) is much larger than on the protein used (one negative charge each 46 residues) and the driving force is the electrical potential. According to recent publications $^{59-61}$ about protein translocation using polymer theory, the molecule needs to be brought to the pore entry and this is achieved because of a combination of diffusion and electrophoretic drift in the vicinity of the pore. The applied voltage needs to be a sufficiently strong force to capture the molecule. Then, the polymer can translocate through a narrow pore since the conformational macromolecule entropy is reduced, resulting in a free-energy barrier. This free-energy barrier is additionally modulated by protein-pore interactions. Up to now, all experimental measurements of these energy barriers with protein channels show a lower barrier for an unfolded protein ${ }^{26,28}$ in comparison to polyelectrolytes. ${ }^{62,63}$ Here, the imposed 
a) Chimera

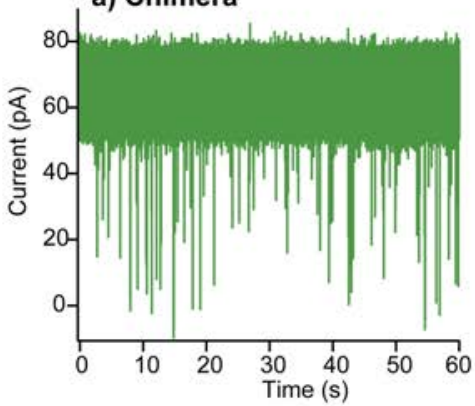

d) Protein-K370C

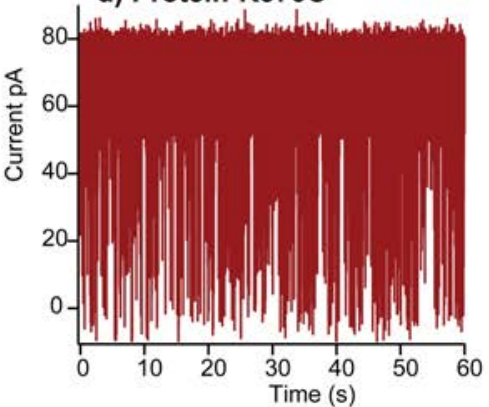

g) Oligonucleotide
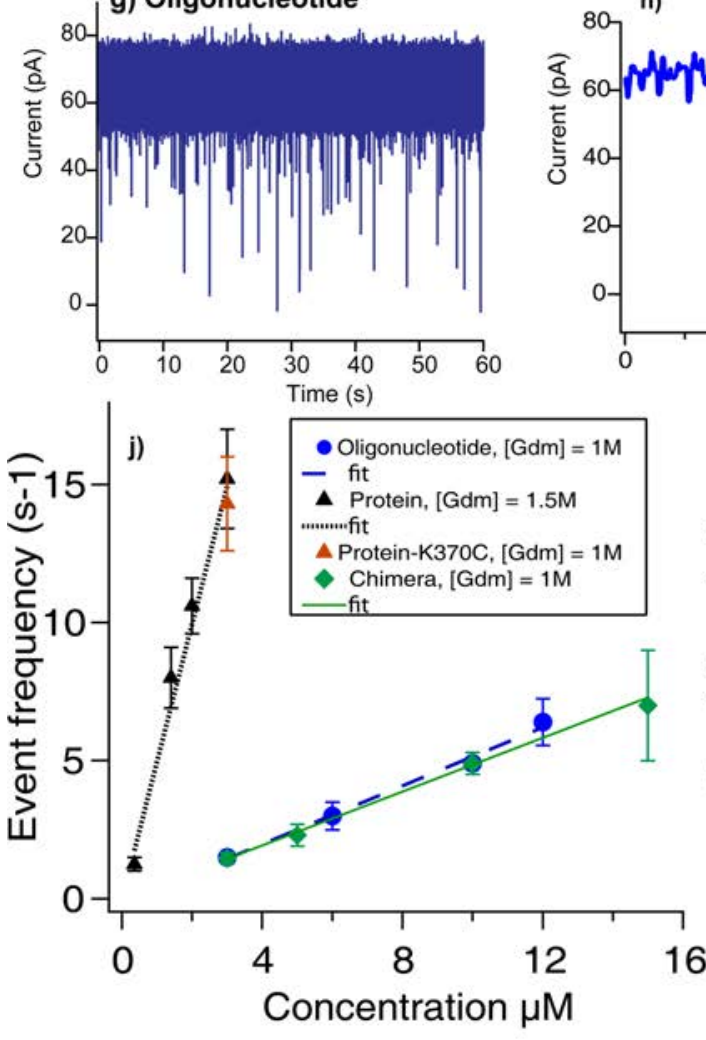

b)

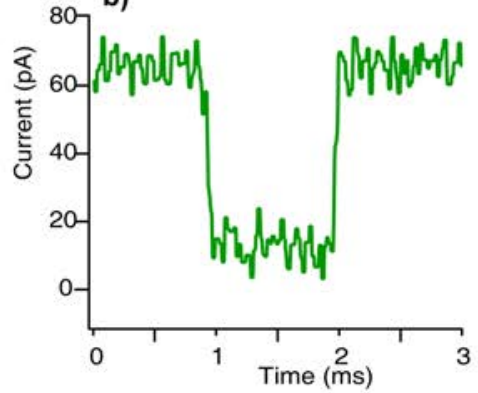

c)
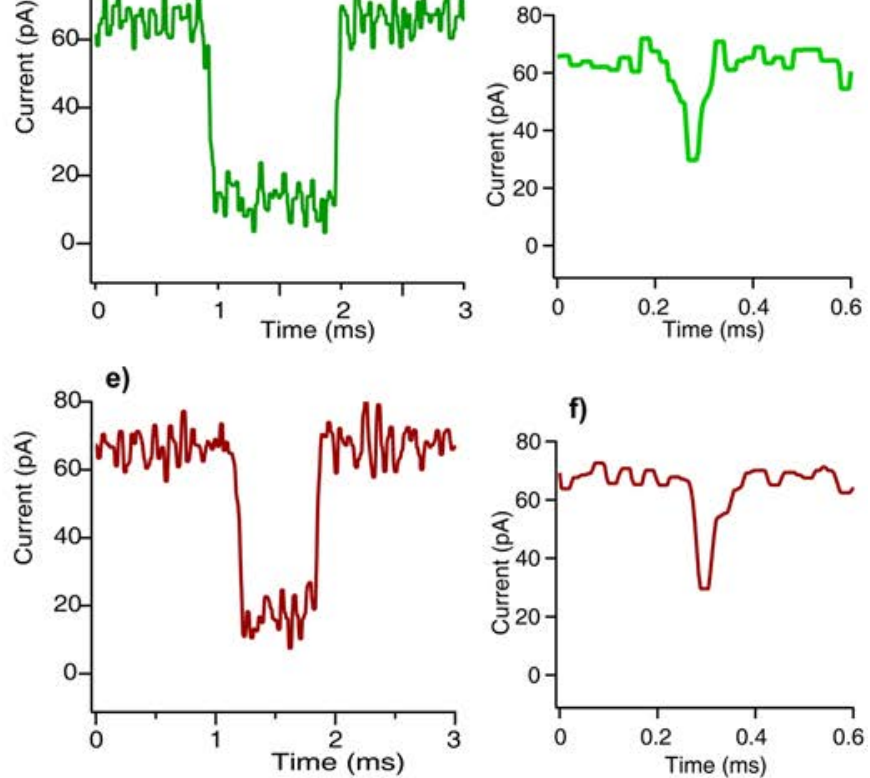

h)
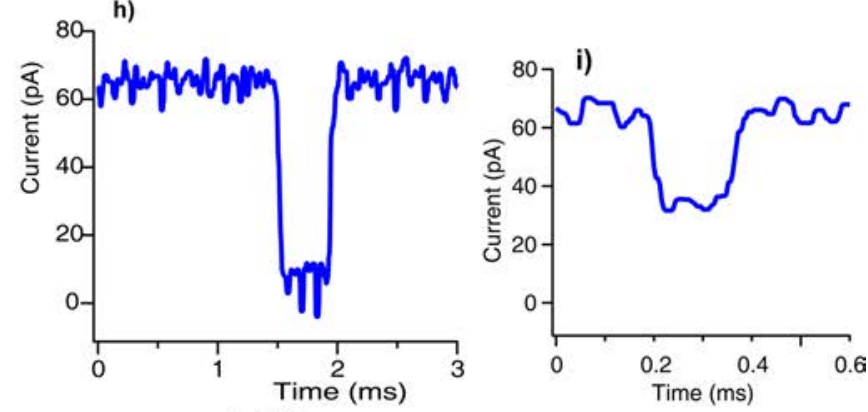

Figure 3. Dynamics of molecules through the aerolysin pore. Comparison of current traces, event frequency, and dwell time of molecules, chimera, MalEK370 C protein, and oligonucleotide, going through the pore. Left panels correspond to $60 \mathrm{~s}$ current recordings, middle panels correspond to long and deep current blockade details and right panels correspond to short and less deep current blockade details: ( $a, b$, and c) chimera, green; (d, e, and f) MaIE K370C, brown (proteins were prereduced with DTT before translocation experiments to be sure any dimer is present in the sample); ( $g, h$, and $i)$ oligonucleotide, blue. (j) Event frequency as a function of molecules concentration, lines are linear fits. (k) Dwell time duration as a function of molecule concentration, lines correspond to linear fits. Experiments are made at $1 \mathrm{M} \mathrm{KCl}, 1 \mathrm{M} \mathrm{Gdm}-\mathrm{HCl}, 5 \mathrm{mM} \mathrm{HEPES} \mathrm{pH} \mathrm{7.4.} \mathrm{Applied} \mathrm{voltage} \mathrm{is} 70 \mathrm{mV}$. Chimera concentration is $5 \mu \mathrm{M}(\mathrm{a}, \mathrm{b}, \mathrm{c})$, protein concentration is $3 \mu \mathrm{M}(\mathrm{d}, \mathrm{e}, \mathrm{f})$, and oligonucleotide concentration is $3 \mu \mathrm{M}$ (g,h,i).

voltage difference, $V=70 \mathrm{mV}$, is low enough to limit the entry of the oligonucleotide into the nanopore by forcing the electrical charge of the aerolysin channel (the overall charge is $-52 e$ ). We are mainly expecting some collision and/or interaction events and a few translocation ones. The most observed events are 
a)
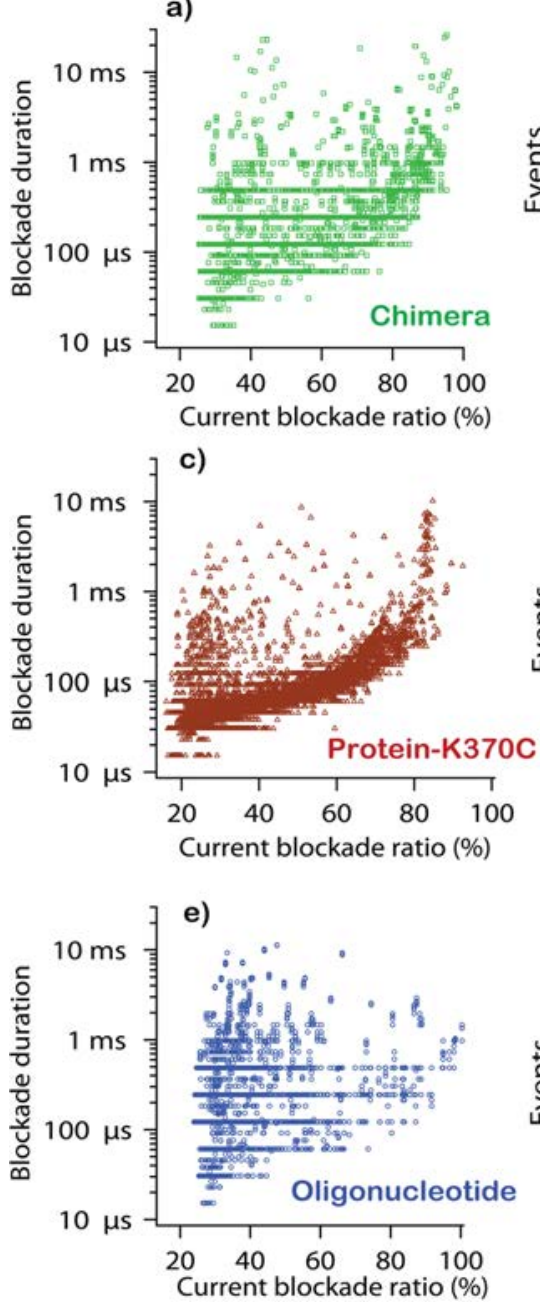

b)

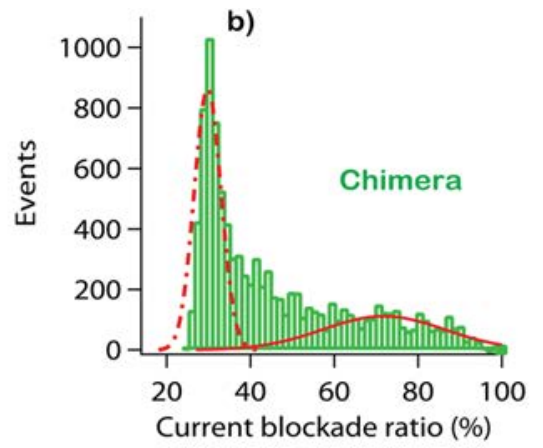

d)

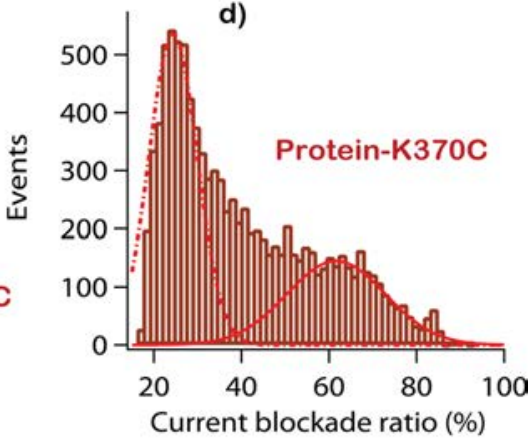

f)

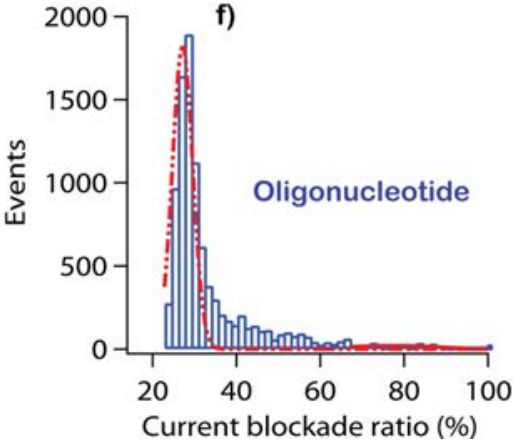

Figure 4. Electrical signal of three kinds of molecules, chimera, protein, and oligonucleotide. Left, scatter plots of blockade duration versus current blockade ratio for each kind of molecule, chimera (a and b) (green); protein (c and d) (brown); and oligonucleotide (e and f) (blue). Right, events distribution versus current blockade ratio. Any kind of molecule has its characteristic blockade ratio. Experiments are made at $1 \mathrm{M} \mathrm{KCl}, 1 \mathrm{M} \mathrm{Gdm}-\mathrm{HCl}, 5 \mathrm{mM} \mathrm{HEPES}$ pH 7.4. Applied voltage is $70 \mathrm{mV}$. Chimera concentration is $5 \mu \mathrm{M}$, protein concentration is $3 \mu \mathrm{M}$, oligonucleotide concentration is $3 \mu \mathrm{M}$. We have fitted with Gaussian function (red color), the distributions of events as a function of current blockade ratio (\%) for chimera, protein, and oligonucleotide, dotted line for the not deep distribution of blockades and full line for the deep distribution of blockades.

TABLE 1. Current Blockade Ratio Determination for Each Molecule Type from the Histograms of Figure $4 b, d, f$

\begin{tabular}{lcc} 
& current blockade ratio (\%) & current blockade ratio (\%) \\
\hline chimera & $30 \pm 3.2$ & $72 \pm 14$ \\
Protein-K370C & $24 \pm 5.6$ & $62 \pm 11.5$ \\
oligonucleotide & $27 \pm 2.5$ & $82 \pm 7$ \\
\hline
\end{tabular}

associated with a low current blockage ratio (Figure $4 \mathrm{e}, \mathrm{f}$ ), collision, or interaction events. For unfolded protein chains, the protein-pore electrostatic interactions are reduced at the pore entry and we observe more translocation events. The electroosmotic flow could also have a role in chimera capture rate, but information about electro-osmotic flow in protein nanopores is lacking. These arguments can possibly explain why the protein enters first into the nanopore in the chimera molecule. A recent work in our laboratory, shows at $10{ }^{\circ} \mathrm{C}$, without denaturing agent, an entry energy barrier of $10 \mathrm{kBT}$ for singlestranded DNA with an aerolysin channel (Payet et al, submitted to $\mathrm{PRL}$ ), and we have previously found $4 \mathrm{kBT}$ for unfolded MalE, at $25{ }^{\circ} \mathrm{C} .{ }^{26}$

Direct Proof of Protein Translocation through a Narrow Protein Nanopore. After obtaining the standard curve (Figure 2b), we proceeded to translocation experiments with chimera in the presence of guanidium hydrochloride $1 \mathrm{M}(\mathrm{Gdm}-\mathrm{HCl})$ to denature the protein. At this concentration of denaturant, the protein (MalE) is completely unfolded according our previous results, using the alpha-hemolysin and aerolysin channel. The unfolded proteins induce current pore blockades, with a duration below $1 \mathrm{~ms}$ and a current blockade ratio around $60 \%-70 \%$. The frequency of events increases 
a)

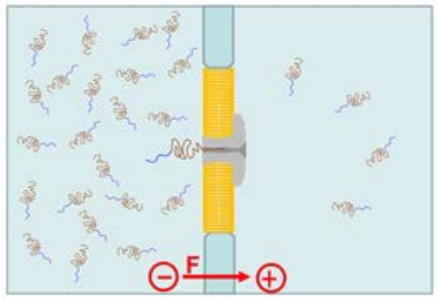

0 b)

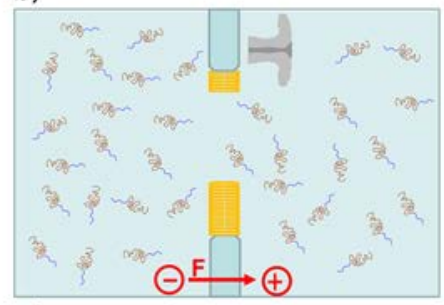

c)
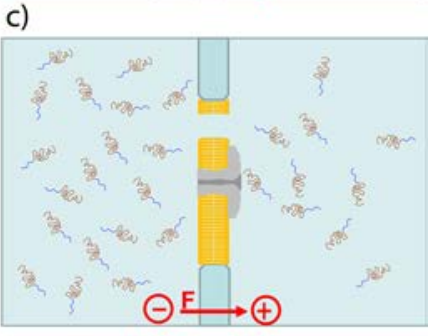

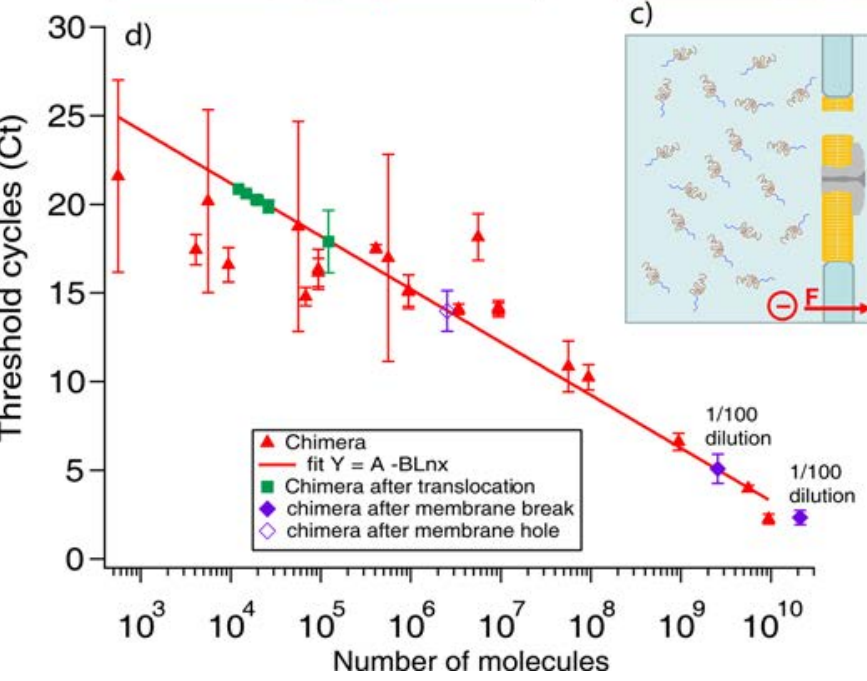

Figure 5. Chimera detection after translocation through an aerolysin nanopore. $(a, b, c)$ Scheme of experimental set up. (a) After a single pore insertion into the lipid bilayer, chimera molecules are incorporated in a cis chamber, voltage is applied to drive molecules through the pore. Membrane remains intact during experiment duration and after trans compartment molecules collection. (b) After several minutes up to few hours of translocation measurements, the membrane is broken or it is broken during trans compartment molecules recovery. (c) After several minutes of translocation measurements, membrane had a hole. (d) Detection of translocated chimera molecules through aerolysin pore; molecules were recovered from the trans chamber and quantified by qRT-PCR. Red line corresponds to the fit of chimera molecules, $y=A-B \operatorname{Ln}(x)$, where $y=C t$, $A=33 \pm 0.4, B=1.29 \pm 0.02$ and $x$ is the number of molecules. Green squares correspond to direct detection and three serial dilutions of $10 \mu \mathrm{M}$ chimera translocation after a 136 min experiment without membrane break.

TABLE 2. Number of Molecules Detected by qRT-PCR after Translocation Experiments

\begin{tabular}{lcccc}
\multicolumn{1}{c}{ molecule } & concentration $(\mu \mathrm{M})$ & membrane status $^{\boldsymbol{a}}$ & \multicolumn{1}{c}{$\mathbf{c t}^{\text {calculated number of molecules }}$} \\
\hline oligonucleotide & 6 & intact & $18.85 \pm 0.35$ & 58196 \\
chimera & 10 & intact & $17.9 \pm 1.76$ & $121699 \pm 11966$ \\
chimera & 5 & broken & n.m. ${ }^{b}$ & n.m. \\
chimera & 15 & hole & $13.98 \pm 1.14^{a}$ & 2531154
\end{tabular}

${ }^{a}$ Membrane status: After several minutes to hours of experiment recording, trans compartment content is collected: intact, membrane is still detected after trans compartment collection; broken, membrane was broken during experiment so we immediately recover the trans compartment content; hole, at the end of the experiment a hole was detected so we stopped recording and recovered trans compartment content. ${ }^{b}$ n.m., not measurable. Fluorescence in qRT-PCR essay is too high to be measured. A $1 / 100$ dilution of these samples give a $\mathrm{Ct}=5.08 \pm 0.82\left(2.5 \times 10^{9}\right.$ molecules $)$ for one experiment and $\mathrm{Ct}=2.34 \pm 0.41\left(2.1 \times 10^{10}\right.$ molecules $)$ for another one.

as the concentration of denaturing agent increases, following a sigmoidal denaturation curve. At $1 \mathrm{M}$ $\mathrm{Gdm}-\mathrm{HCl}$, we have reached the plateau of the unfolding curve. ${ }^{21,28}$

We tried to do recordings as long as the stability of the lipid bilayer allowed us. We introduced different chimera concentrations in the cis chamber of the setup and proceeded with current trace recording at $70 \mathrm{mV}$. The main difficulty is to prevent lipid bilayer breaking or hole formation during sample collection in the trans chamber. If the membrane is broken we cannot measured any current. If we observe a higher current, typically hundred $\mathrm{pA}$ to nano $\mathrm{pA}$, in comparison to the ionic current of a single channel, around $65 \mathrm{pA}$, that suggests either there are multiple pores inserted into the bilayer or a few lipids of the bilayer are detached from the membrane during sample collection. In both cases, the number of molecules estimated by qRT-PCR will be out of range (membrane break) or too high to be in accord with event frequency values detected by electrical current recordings (Figure $5 \mathrm{~d}$ and Table 2 ).

We performed several essays to recover the chimera sample in the trans chamber without membrane breaking. Since PCR is using a DNA polymerase and our 
experimental conditions used $2 \mathrm{M}$ salt $(1 \mathrm{M} \mathrm{KCl}$ and $1 \mathrm{M}$ $\mathrm{Gdm}-\mathrm{HCl}$ ), we dialyzed our sample and concentrated it before amplification measurements (see Methods section for details). After sample preparation we proceeded to qRT-PCR measurement, and the results are shown in Figure 5. We have measured different samples, raw and diluted, from several experiments and we could detect around 10000 to 100000 molecules according to the chimera standard curve. We have also measured oligonucleotide and protein alone going though aerolysin under the same experimental conditions. We could detect oligonucleotide after the qRT-PCR analysis but not protein alone (Table 2 and data not shown). For the oligonucleotide, the number of molecules detected by qRT-PCR after translocation is under $9 \%$ of the number of events estimated with frequency values. This is in agreement with the lowevent population of a deep current blockade ratio (Figure $4 \mathrm{e}, \mathrm{f}$ ). Depending on membrane status at the end of the experiment, quantification analysis showed very different results (Table 2). When we tried to compare the number of molecules detected by PCR after the transport through the aerolysin pore to that obtained using frequencies, the number of molecules, $121699 \pm 11966$, is of the same order of the number of events detected by the electrical signal of current blockade, $83966 \pm 14274$. Frequency analysis was difficult since during recording we had periods where several pores were inserted in the membrane (up to three pores) and not always in the same orientation. Since the frequency of molecules going through stem or vestibule side is not the same, ${ }^{26}$ then we can obtain a quantitative estimation and not an exact measurement. Frequently, the membrane was broken at the end of the experiment or when recovering the trans compartment (Figure 5b) or there was a hole in the membrane (Figure $5 c$ ). The number of molecules detected by qRT-PCR in these cases was higher by at least a factor $10^{5}$ or 100 respectively for a membrane broken or a hole in the membrane than that expected as a function of translocation frequency determined by electrical measurements (Figure $5 d$ and Table 2).

\section{CONCLUSION}

We have designed and produced a monodisperse chimera molecule composed of a recombinant protein with a unique cysteine residue at the $\mathrm{C}$-terminal position covalently linked to a single-stranded DNA oligonucleotide. This chimera allowed us to increase the sensitivity of protein detection by real-time PCR up to 1000 molecules.
We have demonstrated that an unfolded protein, with a radius of the polypeptide chain larger than the nanopore diameter, driven by an electrical applied voltage through a protein channel, aerolysin, is really translocated. This is the first evidence that proteins can enter and go through a protein pore and be directly detected after translocation. We have observed that electrical signature and transport dynamics depend on the nature of the molecule, chimera, protein, or oligonucleotide. In our experimental conditions, the translocation time is longer for chimera in comparison to protein or oligonucleotide.

The new generation of nanopores and nanotubes, with a specific design and manufacture may allow the development of future biotechnology and medical applications. The more challenging application concerns peptide and protein sequencing by nanopores. To achieve this challenge we must control protein unfolding, threading of unfolded polypeptide chain into the nanopore, and the translocation time. Another promising application concerns the development of recombinant protein refolding with a nanopore. The industrial production of recombinant proteins is limited by the incomplete or imperfect folding of the produced proteins. ${ }^{64} \mathrm{~A}$ sequential refolding through the nanopore's exit could be used to assist the renaturation of recombinant proteins. Furthermore, many human diseases have been unable to be diagnosed, and many biomarkers are peptides or proteins. A possible upcoming application is to use nanopores to detect biomarkers in biofluid. Some human diseases are related to partial unfolding or alternative folding, which are known as conformational diseases, and result in reduced life expectancy and quality of life. The nanopores technology can be used to study these conformational diseases.

An open question concerns solid-state nanopores and the ability to detect protein translocation events in terms of capture rate and dwell time, as a function of the filter and acquisition conditions. According to the dynamics models applied and theoretically values expected, the transport could be explained with or without protein-pore interaction, electro-osmotic flow, Brownian diffusion, anomalous diffusion, or a purely electrophoresis behavior. ${ }^{36-44,65,66}$ We plan to apply this approach to native and unfolded protein translocation through narrow solid-state nanopores. In the future, we will work on protein renaturation in the trans compartment by changing its content or adding chaperone molecules to assist recombinant protein refolding.

\section{METHODS}

Chimera Construction and Purification. OCMN5, a single stranded DNA oligonucleotide was synthetically produced by Eurogentec (Eurogentec S.A., Belgium). The 60 nucleotide sequence from bluetongue virus (BTV) ${ }^{56}$ was modified at the $5^{\prime}$ end to bear an amino group and a 6-Carbone linker. The molecular weight of this molecule was $18721 \mathrm{M}^{-1} \mathrm{~cm}^{-1}$, and its molar extinction coefficient $E_{260 \mathrm{~nm}}=588700 \mathrm{M}^{-1} \mathrm{~cm}^{-1}$. 
The MalEK370C mutation was constructed by oligonucleotide mutagenesis using a QuikChangell XL Site-Directed Mutagenesis kit (Stratagene). The corresponding modified protein was produced in Escherichia coli and purified as previously described for wild-type MalE. ${ }^{67}$ Before conjugation, the purified protein was reduced with $25 \mathrm{mM}$ DTT and equilibrated in PBS-EDTA using a PD10 column. After elution, MalEK370C was concentrated using the Vivaspin6 concentrator (Sartorius Stedim Biotech, Germany).

Conjugation is based in a previously described method ${ }^{68}$ using SPDP ( $N$-succinimidyl 3-(2-pyridyldithio) propionate). A scheme that accounts for this method is represented in Figure 1a. In brief, $50 \mathrm{nmol}$ of oligonucleotide in PBS-EDTA was mixed with $20 \mathrm{mM}$ SPDP during $30 \mathrm{~min}$ at room temperature. The excess of nonreacted SPDP was eliminated with a desalting column equilibrated in PBS-EDTA. Fractions containing oligonucleotide (optical density at $260 \mathrm{~nm}$ ) were mixed to $125 \mathrm{nmol}$ of prereduced protein overnight at room temperature under gentle shaking. The reaction product was concentrated and loaded into a gel filtration column Superdex 75 (GE Healthcare) equilibrated in $150 \mathrm{mM} \mathrm{KCl}, 5 \mathrm{mM}$ HEPES at $\mathrm{pH} 7.4$.

Chimera concentration was calculated using extinction coefficients at both 280 and $260 \mathrm{~nm}$. At $280 \mathrm{~nm}$, the extinction coefficient was calculated by the addition of OCMN5 oligonucleotide contribution to the protein extinction coefficient, resulting in $E_{280} \mathrm{~nm}=337520 \mathrm{M}^{-1} \mathrm{~cm}^{-1}$. At $260 \mathrm{~nm}$, the protein contribution to the extinction coefficient of chimera molecules was insignificant in relation to the oligonucleotide one (see above).

Nanopore Setup. Membrane lipid bilayers were made using a previously described method. ${ }^{51,69}$ Both chambers of the set up were filled with $1 \mathrm{~mL}$ of the same buffer, $1 \mathrm{M} \mathrm{KCl}, 1 \mathrm{M} \mathrm{Gdm}-\mathrm{HCl}$, $5 \mathrm{mM}$ HEPES, pH 7.4. Recombinant aerolysin was produced and used for nanopore insertion as previously described. ${ }^{26}$ After one single pore insertion, different chimera, protein or oligonucleotide concentrations were added to the cis compartment in different experiments. Data were recorded for a few hours until the membrane bilayer started to be less stable. Trans compartment content was recovered, without breaking the membrane or after breaking the membrane, to further quantify transported molecules (Figure 5).

lonic current through the aerolysin nanopore was measured using an Axopatch 200B amplifier. Data were filtered at $10 \mathrm{kHz}$ and acquired at $4 \mu \mathrm{s}$ intervals with the DigiData 1322A digitizer coupled to Clamplex software (Axon Instruments, USA). Statistical analysis of the current traces was used to measure blockades duration and frequencies as previously described. ${ }^{70}$

Oligonucleotide and Chimera Molecules Quantification by qRT-PCR. Samples from translocation experiments were dialyzed to DNase and RNase free water at $4{ }^{\circ} \mathrm{C}$. After that, samples were concentrated using Vivaspin6 and Vivaspin500 devices (Sartorius Stedim Biotech, Germany). About $10 \mu \mathrm{L}$ was recovered after dialysis and concentration, and $3 \mu \mathrm{L}$ was used for qRT-PCR. A scheme of a classical RT-PCR protocol adapted to our experimental conditions is shown in Supporting Information, Figure S1.

qRT-PCR was performed using a C100 thermal cycler coupled to a CFX 96 real time system (Biorad). Specific primers for amplification were used. ${ }^{56}$ Amplifications were done in a final volume of $20 \mu \mathrm{L}$ using the SupertScript III Platinium SYBR Green One-Step qRT-PCR kit (Invitrogen). Amplification protocol consisted of $10 \mathrm{~min}$ at $45{ }^{\circ} \mathrm{C}$ followed by a denaturing step of $10 \mathrm{~min}$ at $95^{\circ} \mathrm{C}$ and 40 cycles of denaturing for $15 \mathrm{~s}$ at $95^{\circ} \mathrm{C}$, hybridization and elongation for $1 \mathrm{~min}$ at $60^{\circ} \mathrm{C}$. After amplification a sigmoid curve representing the fluorescence measurement was obtained (Figure 2a). Standard curves were established to quantify transported molecules. The range used in these amplifications goes from 1000 molecules to $10^{10}$ molecules. Known quantities of oligonucleotide alone or chimera were used (Figure 2b). After amplification and acquisition of fluorescence emitted during the amplification process, we set the cycle threshold $(C T)$ in the exponential phase of the sigmoid curve at a level that allowed us to obtain the best regression in standard curves. The fit of the representation of CT as a function of number of molecules was used to calculate the number of transported molecules through the aerolysin nanopore.
Conflict of Interest: The authors declare no competing financial interest.

Supporting Information Available: Supporting figures corresponding to the experimental methods and complementary results. This material is available free of charge via the Internet at http://pubs.acs.org.

Acknowledgment. This work was supported by the French Agence Nationale de Recherche ANR-12-NANO-0012-03 and by C'NANO-NANO K TRANSLOCPROT No. 094251 and by Genopole. We thank Emmanuel Bréard (UMR 1161 AFSSA-ENVA-INRA, France) for the oligonucleotide sequence suggestion. We thank Laurent Bacri for useful discussions and his expertise in data analysis. We thank Micayla Bowman for kindly correcting the language of the manuscript.

\section{REFERENCES AND NOTES}

1. Howorka, S.; Siwy, Z. S. Nanopore Analytics: Sensing of Single Molecules. Chem. Soc. Rev. 2009, 38, 2360-2384.

2. Majd, S.; Yusko, E. C.; Billeh, Y. N.; Macrae, M. X.; Yang, J.; Mayer, M. Applications of Biological Pores in Nanomedicine, Sensing, and Nanoelectronics. Curr. Opin. Biotechnol. 2010, 21, 439-476.

3. Movileanu, L. Interrogating Single Proteins through Nanopores: Challenges and Opportunities. Trends Biotechnol. 2009, 27, 333-341.

4. Oukhaled, A.; Bacri, L.; Pastoriza-Gallego, M.; Betton, J. M.; Pelta, J. Sensing Proteins through Nanopores: Fundamental to Applications. ACS Chem. Biol. 2012, 7, 1935-1949.

5. Reiner, J. E.; Balijepalli, A.; Robertson, J. W. F.; Campbell, J.; Suehle, J.; Kasianowicz, J. J. Disease Detection and Management via Single Nanopore-Based Sensors. Chem. Rev. 2012, 112, 6431-6451.

6. Zimmerberg, J.; Parsegian, V. A. Polymer Inaccessible Volume Changes during Opening and Closing of a VoltageDependent lonic Channel. Nature 1986, 323, 36-39.

7. Gu, L. Q.; Wanunu, M.; Wang, M. X.; McReynolds, L.; Wang, Y. Detection of miRNAs with a Nanopore Single-Molecule Counter. Expert. Rev. Mol. Diagn. 2012, 12, 573-584.

8. Gurnev, P. A.; Nestorovich, E. M. Channel-Forming Bacterial Toxins in Biosensing and Macromolecule Delivery. Toxins 2014, 6, 2483-2540.

9. Haque, F.; Li, J. H.; Wu, H. C.; Liang, X. J.; Guo, P. X. SolidState and Biological Nanopore for Real-Time Sensing of Single Chemical and Sequencing of DNA. Nano Today 2013, 8, 56-74.

10. Stoloff, D. H.; Wanunu, M. Recent Trends in Nanopores for Biotechnology. Curr. Opin. Biotechnol. 2013, 24, 699-704.

11. Yang, Y. Q.; Liu, R. Y.; Xie, H. Q.; Hui, Y. T.; Jiao, R. G.; Gong, Y.; Zhang, Y. Y. Advances in Nanopore Sequencing Technology. J. Nanosci. Nanotechnol. 2013, 13, 4521-4538.

12. Ying, Y. L.; Zhang, X.; Liu, Y.; Xue, M. Z.; Li, H. L.; Long, Y. T. Single Molecule Study of the Weak Biological Interactions between P53 and DNA. Acta Chim. Sin. 2013, 71, 44-50.

13. Movileanu, L. Watching Single Proteins Using Engineered Nanopores. Protein Pept. Lett. 2014, 21, 235-246.

14. Nivala, J.; Marks, D. B.; Akeson, M. Unfoldase-Mediated Protein Translocation through an Alpha-Hemolysin Nanopore. Nat. Biotechnol. 2013, 31, 247-250.

15. Wang, Y.; Zheng, D.; Tan, Q.; Wang, M. X.; Gu, L. Q. Nanopore-Based Detection of Circulating MicroRNAs in Lung Cancer Patients. Nat. Nanotechnol. 2011, 6, 668-674.

16. Wanunu, M.; Dadosh, T.; Ray, V.; Jin, J.; McReynolds, L.; Drndic, M. Rapid Electronic Detection of Probe-Specific MicroRNAs Using Thin Nanopore Sensors. Nat. Nanotechnol. 2010, 5, 807-814.

17. Japrung, D.; Dogan, J.; Freedman, K. J.; Nadzeyka, A.; Bauerdick, S.; Albrecht, T.; Kim, M. J.; Jemth, P.; Edel, J. B. Single-Molecule Studies of Intrinsically Disordered Proteins Using Solid-State Nanopores. Anal. Chem. 2013, 85, 2449-2456.

18. Jetha, N. N.; Wiggin, M.; Marziali, A. Forming an AlphaHemolysin Nanopore for Single-Molecule Analysis. Methods Mol. Biol. 2009, 544, 113-127. 
19. Yusko, E. C.; Prangkio, P.; Sept, D.; Rollings, R. C.; Li, J.; Mayer, M. Single-Particle Characterization of Abeta Oligomers in Solution. ACS Nano 2012, 6, 5909-5919.

20. Freedman, K. J.; Jurgens, M.; Prabhu, A.; Ahn, C. W.; Jemth, P.; Edel, J. B.; Kim, M. J. Chemical, Thermal, and Electric Field Induced Unfolding of Single Protein Molecules Studied Using Nanopores. Anal. Chem. 2011, 83, 5137-5144.

21. Merstorf, C.; Cressiot, B.; Pastoriza-Gallego, M.; Oukhaled, A.; Betton, J. M.; Auvray, L.; Pelta, J. Wild Type, Mutant Protein Unfolding and Phase Transition Detected by SingleNanopore Recording. ACS Chem. Biol. 2012, 7, 652-658.

22. Rodriguez-Larrea, D.; Bayley, H. Multistep Protein Unfolding During Nanopore Translocation. Nat. Nanotechnol. 2013, 8, 288-295.

23. Baaken, G.; Ankri, N.; Schuler, A. K.; Ruhe, J.; Behrends, J. C. Nanopore-Based Single-Molecule Mass Spectrometry on a Lipid Membrane Microarray. ACS Nano 2011, 5, 80808088.

24. Reiner, J. E.; Kasianowicz, J. J.; Nablo, B. J.; Robertson, J. W. F. Theory for Polymer Analysis Using Nanopore-Based Single-Molecule Mass Spectrometry. Proc. Natl. Acad. Sci. U.S.A 2010, 107, 12080-12085.

25. Mohammad, M. M.; Prakash, S.; Matouschek, A.; Movileanu, L. Controlling a Single Protein in a Nanopore through Electrostatic Traps. J. Am. Chem. Soc. 2008, 130, 4081-4088.

26. Pastoriza-Gallego, M.; Rabah, L.; Gibrat, G.; Thiebot, B.; van der Goot, F. G.; Auvray, L.; Betton, J. M.; Pelta, J. Dynamics of Unfolded Protein Transport through an Aerolysin Pore. J. Am. Chem. Soc. 2011, 133, 2923-2931.

27. Singh, P. R.; Barcena-Uribarri, I.; Modi, N.; Kleinekathofer, U.; Benz, R.; Winterhalter, M.; Mahendran, K. R. Pulling Peptides across Nanochannels: Resolving Peptide Binding and Translocation through the Hetero-oligomeric Channel from Nocardia farcinica. ACS Nano 2012, 6, 10699-10707.

28. Oukhaled, G.; Mathe, J.; Biance, A. L.; Bacri, L.; Betton, J. M.; Lairez, D.; Pelta, J.; Auvray, L. Unfolding of Proteins and Long Transient Conformations Detected by Single Nanopore Recording. Phys. Rev. Lett. 2007, 98, 158101-158104.

29. Payet, L.; Martinho, M.; Pastoriza-Gallego, M.; Betton, J. M.; Auvray, L.; Pelta, J.; Mathe, J. Thermal Unfolding of Proteins Probed at the Single Molecule Level Using Nanopores. Anal. Chem. 2012, 84, 4071-4076.

30. Mereuta, L.; Roy, M.; Asandei, A.; Lee, J. K.; Park, Y.; Andricioaei, l.; Luchian, T. Slowing Down Single-Molecule Trafficking through a Protein Nanopore Reveals Intermediates for Peptide Translocation. Sci. Rep. 2014, 4, 3885.

31. Stefureac, R. I.; Lee, J. S. Nanopore Analysis of the Folding of Zinc Fingers. Small 2008, 4, 1646-1650.

32. Rotem, D.; Jayasinghe, L.; Salichou, M.; Bayley, H. Protein Detection by Nanopores Equipped with Aptamers. J. Am. Chem. Soc. 2012, 134, 2781-2787.

33. Soskine, M.; Biesemans, A.; Moeyaert, B.; Cheley, S.; Bayley, H.; Maglia, G. An Engineered ClyA Nanopore Detects Folded Target Proteins by Selective External Association and Pore Entry. Nano Lett. 2012, 12, 4895-4900.

34. Mohammad, M. M.; lyer, R.; Howard, K. R.; Mcpike, M. P.; Borer, P. N.; Movileanu, L. Engineering a Rigid Protein Tunnel for Biomolecular Detection. J. Am. Chem. Soc. 2012, 134, 9521-9531.

35. Soskine, M.; Biesemans, A.; De Maeyer, M.; Maglia, G. Tuning the Size and Properties of ClyA Nanopores Assisted by Directed Evolution. J. Am. Chem. Soc. 2013, 135, 1345613463.

36. Han, A.; Schurmann, G.; Mondin, G.; Bitterli, R. A.; Hegelbach, N. G.; de Rooij, N. F.; Staufer, U. Sensing Protein Molecules Using Nanofabricated Pores. Appl. Phys. Lett. 2006, 88, 093901-093903.

37. Firnkes, M.; Pedone, D.; Knezevic, J.; Doblinger, M.; Rant, U. Electrically Facilitated Translocations of Proteins through Silicon Nitride Nanopores: Conjoint and Competitive Action of Diffusion, Electrophoresis, and Electroosmosis. Nano Lett. 2010, 10, 2162-2167.

38. Fologea, D.; Ledden, B.; McNabb, D. S.; Li, J. Electrical Characterization of Protein Molecules by a Solid-State Nanopore. Appl. Phys. Lett. 2007, 91, 539011-539013.
39. Oukhaled, A.; Cressiot, B.; Bacri, L.; Pastoriza-Gallego, M.; Betton, J. M.; Bourhis, E.; Jede, R.; Gierak, J.; Auvray, L.; Pelta, J. Dynamics of Completely Unfolded and Native Proteins through Solid-State Nanopores as a Function of Electric Driving Force. ACS Nano 2011, 5, 3628-3638.

40. Talaga, D. S.; Li, J. Single-Molecule Protein Unfolding in Solid State Nanopores. J. Am. Chem. Soc. 2009, 131, 92879297.

41. Plesa, C.; Kowalczyk, S. W.; Zinsmeester, R.; Grosberg, A. Y.; Rabin, Y.; Dekker, C. Fast Translocation of Proteins through Solid State Nanopores. Nano Lett. 2013, 13, 658-663.

42. Larkin, J.; Henley, R. Y.; Muthukumar, M.; Rosenstein, J. K.; Wanunu, M. High-Bandwidth Protein Analysis Using SolidState Nanopores. Biophys. J. 2014, 106, 696-704.

43. Niedzwiecki, D. J.; Grazul, J.; Movileanu, L. Single-Molecule Observation of Protein Adsorption onto an Inorganic Surface. J. Am. Chem. Soc. 2010, 132, 10816-10822.

44. Freedman, K. J.; Haq, S. R.; Edel, J. B.; Jemth, P.; Kim, M. J. Single Molecule Unfolding and Stretching of Protein Domains inside a Solid-State Nanopore by Electric Field. Sci.Rep. 2013, 3, 1638.

45. Sexton, L. T.; Horne, L. P.; Sherrill, S. A.; Bishop, G. W.; Baker, L. A.; Martin, C. R. Resistive-Pulse Studies of Proteins and Protein/Antibody Complexes Using a Conical Nanotube Sensor. J. Am. Chem. Soc. 2007, 129, 13144-13152.

46. Siwy, Z.; Trofin, L.; Kohli, P.; Baker, L. A.; Trautmann, C.; Martin, C. R. Protein Biosensors Based on Biofunctionalized Conical Gold Nanotubes. J. Am. Chem. Soc. 2005, 127, 5000-5001.

47. Li, W.; Bell, N. A. W.; Hernandez-Ainsa, S.; Thacker, V. V.; Thackray, A. M.; Bujdoso, R.; Keyser, U. F. Single Protein Molecule Detection by Glass Nanopores. ACS Nano 2013, 7, 4129-4134.

48. Yusko, E. C.; Johnson, J. M.; Majd, S.; Prangkio, P.; Rollings, R. C.; Li, J.; Yang, J.; Mayer, M. Controlling Protein Translocation through Nanopores with Bio-inspired Fluid Walls. Nat. Nanotechnol. 2011, 6, 253-260.

49. Wei, R. S.; Gatterdam, V.; Wieneke, R.; Tampe, R.; Rant, U. Stochastic Sensing of Proteins with Receptor-Modified Solid-State Nanopores. Nat. Nanotechnol. 2012, 7, 257263.

50. Koriazova, L. K.; Montal, M. Translocation of Botulinum Neurotoxin Light Chain Protease through the Heavy Chain Channel. Nat. Struct. Biol. 2003, 10, 13-18.

51. Kasianowicz, J. J.; Brandin, E.; Branton, D.; Deamer, D. W. Characterization of Individual Polynucleotide Molecules Using a Membrane Channel. Proc. Natl. Acad. Sci. U.S.A 1996, 93, 13770-13773.

52. Bikwemu, R.; Wolfe, A. J.; Xing, X. J.; Movileanu, L. Facilitated Translocation of Polypeptides through a Single Nanopore. J. Phys-Condens. Matter 2010, 22, 454117.

53. Goodrich, C. P.; Kirmizialtin, S.; Huyghues-Despointes, B. M.; Zhu, A. P.; Scholtz, J. M.; Makarov, D. E.; Movileanu, L. Single-Molecule Electrophoresis of Beta-Hairpin Peptides by Electrical Recordings and Langevin Dynamics Simulations. J. Phys. Chem. B 2007, 111, 3332-3335.

54. Stefureac, R.; Long, Y. T.; Kraatz, H. B.; Howard, P.; Lee, J. S. Transport of Alpha-Helical Peptides through AlphaHemolysin and Aerolysin Pores. Biochemistry 2006, 45, 9172-9179.

55. Krantz, B. A.; Melnyk, R. A.; Zhang, S.; Juris, S. J.; Lacy, D. B.; Wu, Z. Y.; Finkelstein, A.; Collier, R. J. A Phenylalanine Clamp Catalyzes Protein Translocation through the Anthrax Toxin Pore. Science 2005, 309, 777-781.

56. Toussaint, J. F.; Sailleau, C.; Breard, E.; Zientara, S.; De Clercq, K. Bluetongue Virus Detection by Two RealTime RT-qPCRs Targeting Two Different Genomic Segments. J. Virol. Meth. 2007, 140, 115-123.

57. Burbulis, I.; Yamaguchi, K.; Gordon, A.; Carlson, R.; Brent, R. Using Protein-DNA Chimeras to Detect and Count Small Numbers of Molecules. Nat. Methods 2005, 2, 31-37.

58. Wilmsen, H. U.; Pattus, F.; Buckley, J. T. Aerolysin, a Hemolysin from Aeromonas Hydrophila, Forms VoltageGated Channels in Planar Lipid Bilayers. J. Membr. Biol. 1990, 115, 71-81. 
59. Makarov, D. E. Computational and Theoretical Insights into Protein and Peptide Translocation. Protein Pept. Lett. 2014, 21, 217-226.

60. Muthukumar, M. Communication: Charge, Diffusion, and Mobility of Proteins through Nanopores. J. Chem. Phys. 2014, 141, 081104.

61. Muthukumar, M. Macromolecular Mechanisms of Protein Translocation. Protein Pept. Lett. 2014, 21, 209-216.

62. Gibrat, G.; Pastoriza-Gallego, M.; Thiebot, B.; Breton, M. F.; Auvray, L.; Pelta, J. Polyelectrolyte Entry and Transport through an Asymmetric alpha-Hemolysin Channel. J. Phys. Chem. B 2008, 112, 14687-91.

63. Henrickson, S. E.; Misakian, M.; Robertson, B.; Kasianowicz, J. J. Driven DNA Transport into an Asymmetric NanometerScale Pore. Phys. Rev. Lett. 2000, 85, 3057-3060.

64. Rosano, G. L.; Ceccarelli, E. A. Recombinant Protein Expression in Escherichia coli: Advances and Challenges. Front. Microbiol. 2014, 5, 172.

65. Cressiot, B.; Oukhaled, A.; Patriarche, G.; Pastoriza-Gallego, M.; Betton, J. M.; Auvray, L.; Muthukumar, M.; Bacri, L.; Pelta, J. Protein Transport through a Narrow Solid-State Nanopore at High Voltage: Experiments and Theory. ACS Nano 2012, 6, 6236-6243.

66. Muthukumar, M. Polymer Translocation; CRC Press: Boca Raton, FL, 2011.

67. Raffy, S.; Sassoon, N.; Hofnung, M.; Betton, J. M. Tertiary Structure-Dependence of Misfolding Substitutions in Loops of the Maltose-Binding Protein. Protein Sci. 1998, 7, 2136-2142.

68. Kukolka, F.; Niemeyer, C. M. Synthesis of Fluorescent Oligonucleotide-EYFP Conjugate: Towards Supramolecular Construction of Semisynthetic Biomolecular Antennae. Org. Biomol. Chem. 2004, 2, 2203-2206.

69. Montal, M.; Mueller, P. Formation of Bimolecular Membranes from Lipid Monolayers and a Study of Their Electrical Properties. Proc. Natl. Acad. Sci. U.S.A. 1972, 69, 3561-3566.

70. Pastoriza-Gallego, M.; Gibrat, G.; Thiebot, B.; Betton, J. M.; Pelta, J. Polyelectrolyte and Unfolded Protein Pore Entrance Depends on the Pore Geometry. Biochim. Biophys. Acta 2009, 1788, 1377-1386. 